\title{
Sistemas de regadío tradicional del Padul y su laguna
}

\author{
Jenny Pérez Marrero ${ }^{1}$ e Isabel Bestué Cardiel $^{2}$ \\ ${ }^{1}$ Universidad de Cádiz, ${ }^{2}$ Universidad de Granada \\ Miembros del proyecto de investigación RIPARIA, HAR2011-26778 \\ jennyperezm@gmail.com, ibestue@gmail.com
}

\begin{abstract}
Resumen. El presente trabajo plantea una revisión de lo hasta ahora publicado sobre el regadío tradicional del valle del Padul desde el punto de vista del diseño hidráulico de estos sistemas tradicionales, para intentar aportar más datos para su conocimiento. La metodología plantea el registro de toda la información existente y su análisis en el territorio a través del uso de los sistemas de información geográfica SIG, asociándolo a los diferentes núcleos de población asentados en el entorno a lo largo de la historia, además de su relación con la laguna como elemento determinante en la ampliación del área cultivable anterior a su proceso de desecación. Se plantea una metodología de estudio que relaciona la capacidad hidráulica de la acequia de al-Hagia con el espacio cultivable y los tipos de cultivo.
\end{abstract}

Palabras clave: Regadío, Riparia, Humedal, Patrimonio Hidráulico, Padul.

\begin{abstract}
This paper is a review of what has been published to date on traditional irrigation in Padul valley from the hydraulic design perspective of these traditional systems in order to supply more data for your knowledge. The suggested methodology provides the study of all the existing information, its analysis on the territory through the use of geographic information systems GIS and its relation to the various population centres which have been settling in this area throughout history, as well as its relationship with the lagoon as a determinant in the expansion of arable land before its drying process. We suggest a study methodology that connects the hydraulic capacity of Al-Hagia ditch with the arable area and the crop types.
\end{abstract}

Keywords: Irrigation, Riparian, Wetland, Hydraulic Heritage, Padul.

\section{Introducción}

Los sistemas de regadío tradicionales del Padul han sido desde la edad media la base del desarrollo agrícola de la zona. Es probable que la abundancia del agua en el Valle y la fertilidad de su suelo fuesen algunos de los motivos por los cuales diferentes civilizaciones se asentaron en este entorno. El uso sistemático y continuo del agua para poner en riego una importante cantidad de tierra de la Depresión del Padul continua hasta la actualidad, siendo en la época nazarí y posteriormente en el siglo XVIII, donde debió alcanzar su máximo apogeo debido a la ampliación de la superficie cultivable resultado de la desecación de su laguna.

El presente trabajo plantea una revisión de esta hidráulica productiva tradicional enfocando el estudio en los espacios irrigados en el Padul anteriores al siglo XVI, con el objeto de obtener nuevos datos para su conocimiento como lo son: la superficie cultivada, las características de sus conducciones, la cantidad de agua empleada en el sistema y la relación con la población de la alquería medieval. Se presenta como un ensayo de un estudio multidisciplinar que parte de los principios de la arqueología hidráulica y que da un paso adelante en el análisis de la información desde el punto de vista de la ingeniería hidráulica, haciendo uso de los Sistemas de Información Geográficas para el registro y análisis de la información territorial.

Se debe considerar este estudio como un primer acercamiento, al tratarse de un tema complejo en el que intervienen muchas variables de diferentes campos, limitado a un espacio concreto en el que se llegarán a unas primeras conclusiones que deberán ser contrastadas y completadas con trabajos más profundos. 


\section{Objetivos y metodología}

El presente trabajo plantea el estudio de los sistemas de regadío más antiguos de la alquería del Padul empleando los principios generales de la arqueología hidráulica (Kirchner y Navarro, 1996) y haciendo uso de los Sistemas de Información Geográfica (SIG) para el registro y análisis de la información.

La investigación parte de la revisión y análisis de las fuentes documentales que tratan el tema de los regadíos tradicionales del Padul, principalmente el libro del Apeo del Padul de 1571'. La información asociada al objeto de estudio extraída de las fuentes escritas ha sido volcada en la cartografía actualizada correspondiente en un $\mathrm{SIG}^{2}$. Una vez registrada toda la información en los nuevos mapas confeccionados se procede al reconocimiento en campo de una serie de elementos a través de un sistema de posicionamiento móvil GPS, como antecedente a la prospección hidráulica del sistema $a^{3}$. Dentro del trabajo de campo se registran los yacimientos arqueológicos asociados a la presencia de grupos humanos dentro del ámbito de estudio.

Además de los datos anteriores, se almacena en el SIG diversa documentación planimétrica actual e histórica digitalizada, la última ortofotografía del territorio del Padul año 2010-2011 del PNOA del IGN, en conjunto con la ortofotografía más antigua, correspondiente al vuelo americano de 1956-1957.

Una vez obtenida la planimetría digital del área irrigada en el siglo XVI se pasa a la fase de análisis de la información, se plantean las posibles transformaciones del territorio para adaptarse al uso agrícola y la relación espacial de estas áreas con los núcleos habitados. Para la confección de esta hipótesis se utiliza la información del ámbito ocupado por la "La Laguna" anterior a su último proceso de desecación.

Con los datos recopilados en campo sobre una de las acequias principales de un subsistema que se conservan en la actualidad: pendientes longitudinales y las dimensiones transversales de los canales, se realiza una primera estimación del caudal de agua transportada por esta red y su relación con su superficie de cultivo, en una especie de simulación del sistema de regadío que aporte nuevos datos sobre la cantidad de agua empleada para el desarrollo de sus actividades agrícolas.

\footnotetext{
1 El libro del Apeo del Padul (Ferrer 1994) y el Catastro del Marqués de la Ensenada de 1752 son los documentos base para el estudio de los sistemas de regadío del Padul.

2 "No solo se trata de documentar aisladamente los elementos sino obtener una información global del sistema hidráulico" (Kirchner \& Navarro 1996, p.98).

3 "La prospección hidráulica consiste en un minucioso y exhaustivo trabajo de campo encaminado a la reconstrucción planimétrica de todo el perímetro irrigado en su estado actual y los elementos que lo componen: captación, acequia principal, ramales de derivación, partidores, límites de las terrazas o parcelas, albercas y emplazamientos de molinos" (Kirchner \& Navarro 1996, p.99).
} 


\section{Breve descripción del territorio, aspectos geológicos}

\subsection{La depresión del Padul}

La depresión del Padul se encuentra a $20 \mathrm{Km}$ aproximadamente al sur de la ciudad de Granada, dentro del Valle del Lecrín que forma parte de Sierra Nevada y de la Cordillera Penibética.

El Valle del Lecrín está delimitado por Sierra Nevada al noreste, por las sierras de los Guájares y de la Almijara al sur y por la Meseta de las Albuñuelas al oeste. Cuenta con una serie de unidades morfológicas menores entre las que se encuentra la Depresión del Padul, una fosa tectónica que se formó en el Mioceno en la Era Terciaria y que sufrió una serie de modificaciones durante el Plioceno y el Cuaternario (García 2011, p.16). Las fallas que delimitan la fosa tectónica son el labio nororiental de Sierra Nevada y el suroccidental, el correspondiente juego de fallas antitéticas, el Cerro de los Molinos (Carrasco 1998, p.34).

La división del Valle del Lecrín en dos partes fue originada por el río Dúrcal que nace en la sierra y que cuenta con una extraordinaria capacidad erosiva. Los materiales depositados por el río a su salida de la sierra separaron la parte alta de la fosa tectónica formándose la Depresión de Padul, un área que quedo completamente cerrada en forma de cubeta de poca profundidad (Carrasco 1998, p.34).

La Depresión del Padul quedo convertida en un lago donde los materiales orgánicos de los bordes serranos y de la propia vegetación lacustre, formaron durante el Plioceno y Cuaternario, materiales propios de la carbonización incompleta, constituyéndose entonces enormes depósitos de turba (García 2011, p.17).

Hidrogeológicamente la Depresión de Padul forma una cuenca endorreica donde confluyen la descarga de dos acuíferos y el agua de la escorrentía de las elevaciones circundantes. Los acuíferos son de tipo permeable formados por dolomías alpujárrides y calizas miocénicas (García 2011, p.19), son los de la Sierra de Manar y el del Cerro de los Molinos (Carrasco 1998, p.34).

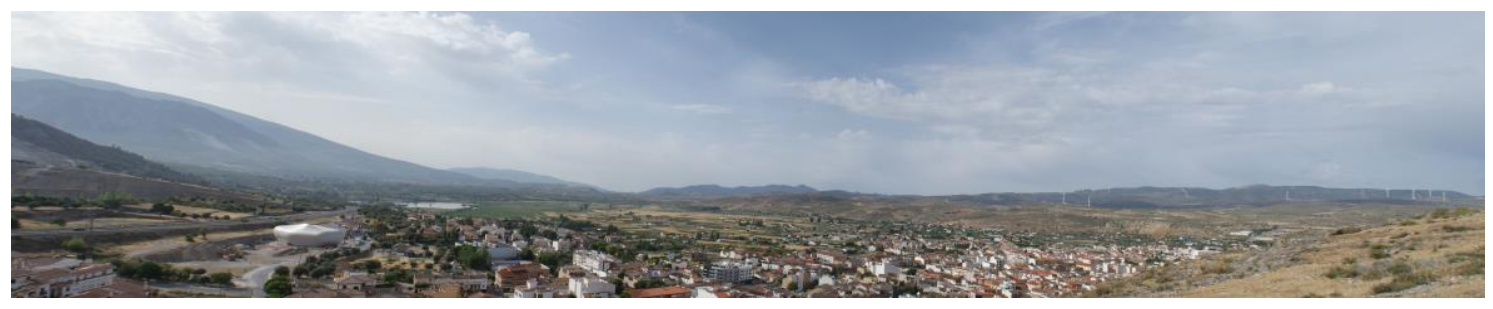

Fig. 1. Vista panorámica de la depresión del Padul.

\subsection{La laguna del Padul}

Dentro de la fosa tectónica del Padul se encuentra una laguna conocida como "Laguna del Padul o del Conde" (Villegas 1967, p.561) de dimensiones máximas 2,5 km de ancho por 3,5 $\mathrm{km}$ de largo (Delgado 2010, p.48), uno de los elementos responsables de la riqueza agrícola de la zona y que cuenta con una historia propia. 
El humedal del Padul se formó debido a los procesos geológicos antes descritos quedando delimitado por dos fallas: la falla del Padul - Niguelas y las fallas del límite del cerro de los Molinos. La falla del Padul - Niguelas es la que define el límite con Sierra Nevada y es muy activa reportando un salto de $250 \mathrm{~m}$ en la zona de la laguna, mientras que las del lado opuesto son poco activas. Esta situación hace que los sedimentos de la fosa tectónica donde se asienta sean bastante asimétricos (Delgado 2010, pp.49-50).

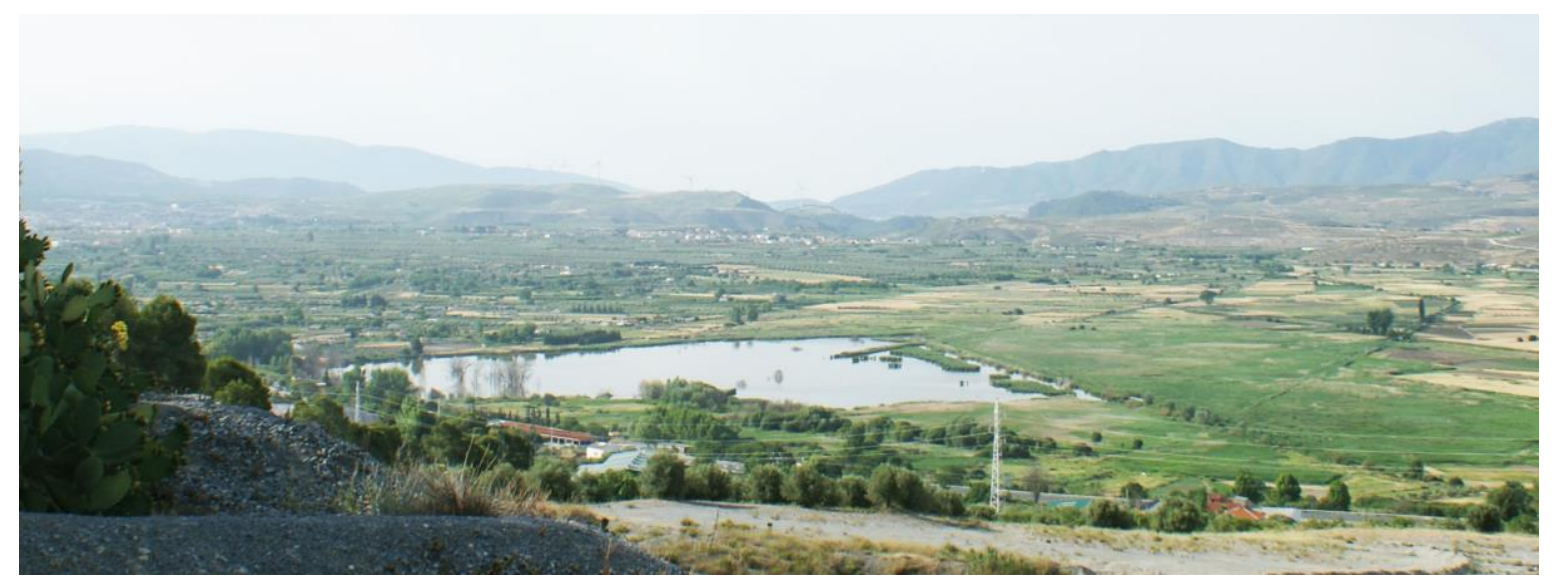

Fig. 2. Vista panorámica del Humedal del Padul desde la Cantera.

La laguna ya se encontraba formada en el Cuaternario y presentaba muy poca profundidad lo que permitió el desarrollo de la típica vegetación lacustre. Al caer la vegetación a la laguna sin completar su proceso de carbonatación hizo posible, junto con otros factores, que se forme la turba. Los depósitos de turba se registran en toda la superficie que ocupó la laguna y se alternan con capas de tipo mineral lo que sugiere que existieron períodos de tiempo en los cuales el humedal estuvo desprovisto de vegetación, bien por cambios climáticos o por el aumento de la profundidad del agua (Delgado 2010, p.50).

En cuanto a su historia, la laguna del Padul ha sido un lugar estratégico para diferentes culturas. Desde época prehistórica se han ocupado sus inmediaciones como lo atestigua la vía íbero-romana labrada en la roca del cerro de los Molinos. De época romana existen referencias documentales de la ocupación de sus inmediaciones "in Domo ad Paludem" como lugar de descanso de las tropas de Fabio Aureo Emilio tras la batalla de Munda por cincuenta días(Delgado 2010, pp.51-52).

Con el paso del tiempo y el desarrollo de las civilizaciones en el entorno del humedal es probable que se realizara la primera desecación de la laguna, en el período nazarí,tal y como consta en el libro del Apeo del Padul de 1571 según el testimonio de varias personas. La laguna vuelve a recuperar su territorio años más tarde, anegando toda la superficie quizás por la falta de la labores de mantenimiento de los drenajes como consecuencia de los enfrentamientos bélicos de la Conquista Castellana (Delgado 2010, p.52).

El humedal del Padul sufre una segunda desecación a finales del siglo XVIII según un proyecto que reposa en los Libros del Cabildo de Granada de 1779. Para ese momento el Conde de Villamena de Cozvíjar era el propietario de casi toda la extensión de la laguna que citan debió ser de 16.000 a 1.8000 marjales. La desecación se realizó a través de canalizaciones o "madres" que unidas forman el río de la Laguna o del Padul (Villegas 1967, pp.566-567). Tras el proceso de desecación el Conde de Villamena inicia un proceso de parcelación del 
espacio desecado en minifundios inferiores a media hectárea que arrendó a un gran número de colonos (Delgado 2010, pp.53-54).

El proceso de desecación antes descrito permitió el desarrollo de una extensa vega de cultivo que alcanzó su máximo desarrollo en el siglo XX pilar fundamental de la economía del Padul. A partir de 1970 se inicia un proceso de resurgir de la laguna, producto del abandono de algunas explotaciones y del continuo hundimiento de la fosa tectónica que se contabiliza en un aumento del área del humedal hasta unos $800.000 \mathrm{~m}^{2}$, unas $80 \mathrm{Ha}$ para 1980 (Delgado 2010, p.57).

Otro hecho que ha favorecido la permanecía del humedal después de su segunda desecación es que los canales de desagüe siempre han sido insuficientes, quedando áreas siempre inundadas en las inmediaciones al Ojo Oscuro, al Hoyo del Clavel y en las dos turberas (Villegas 1967, p.568).

Actualmente la laguna del Padul cuenta con un máximo grado de protección inserta en el Parque Natural de Sierra Nevada desde 1989 y desde el 2006 está incluida en el convenio Ramsar.

\section{Reseña histórica del poblamiento del Padul}

El estado del conocimiento de la ocupación del territorio del Padul es un tema abierto debido a la poca y dispersa información documental y arqueológica existente. Actualmente se conoce que el territorio de la depresión del Padul ha sido un espacio constantemente habitado por diferentes grupos culturales desde la prehistoria.

Los yacimientos arqueológicos asociados a los primeros asentamientos en las inmediaciones de la laguna del Padul atestiguan la presencia de grupos humanos desde el Bronce Final. La ocupación de este territorio continuó en los períodos: preibérico, el protoibérico y durante el Ibérico Pleno, como lo demuestran los restos de materiales localizados en el yacimiento de los Molinos (Rodríguez 1985; Carrasco 1998, pp.101-119). La población ibérica oppidum que debió existir en las inmediaciones de la laguna debe ser del VI - V a.C. debió contar con un vía de comunicación labrada en la roca que fue utilizada también en época romana ubicada en el Cerro de los Molinos (Delgado 2010, p.51).

De la época romana las fuentes clásicas no mencionan núcleos de población importantes en el Valle del Lecrín, la información que se conoce para este período histórico es la que aporta la arqueología, a través del estudio de un par de yacimientos: el de los Molinos y el de las Viñas. No obstante, el nombre de "El Padul" es de procedencia latina y quiere decir laguna o charca ${ }^{4}$. A partir de estos datos y del análisis de los restos materiales encontrados en los yacimientos antes citados se deduce que la población originalmente se debió asentar en la zona de los Molinos y que posteriormente se trasladaría a quinientos metros al norte, hacia el yacimiento de las Viñas, quedando el emplazamiento original ocupado por la Necrópolis Romana. Los restos materiales encontrados en el yacimiento de las Viñas son indicios claros de la existencia de una villae de época imperial (Jabaloy 1985).

\footnotetext{
4 “El nombre del Padul es muy antiguo, es de época romana y todos sabemos que en el año 218, antes de Jesucristo los romanos comenzaron la ocupación de la Península Ibérica. Cuando los romanos llegaron al lugar y vieron la gran laguna, le pusieron el nombre de Paludem, que quiere decir «laguna» «charca»" (Carrasco 1998, p.17).
} 


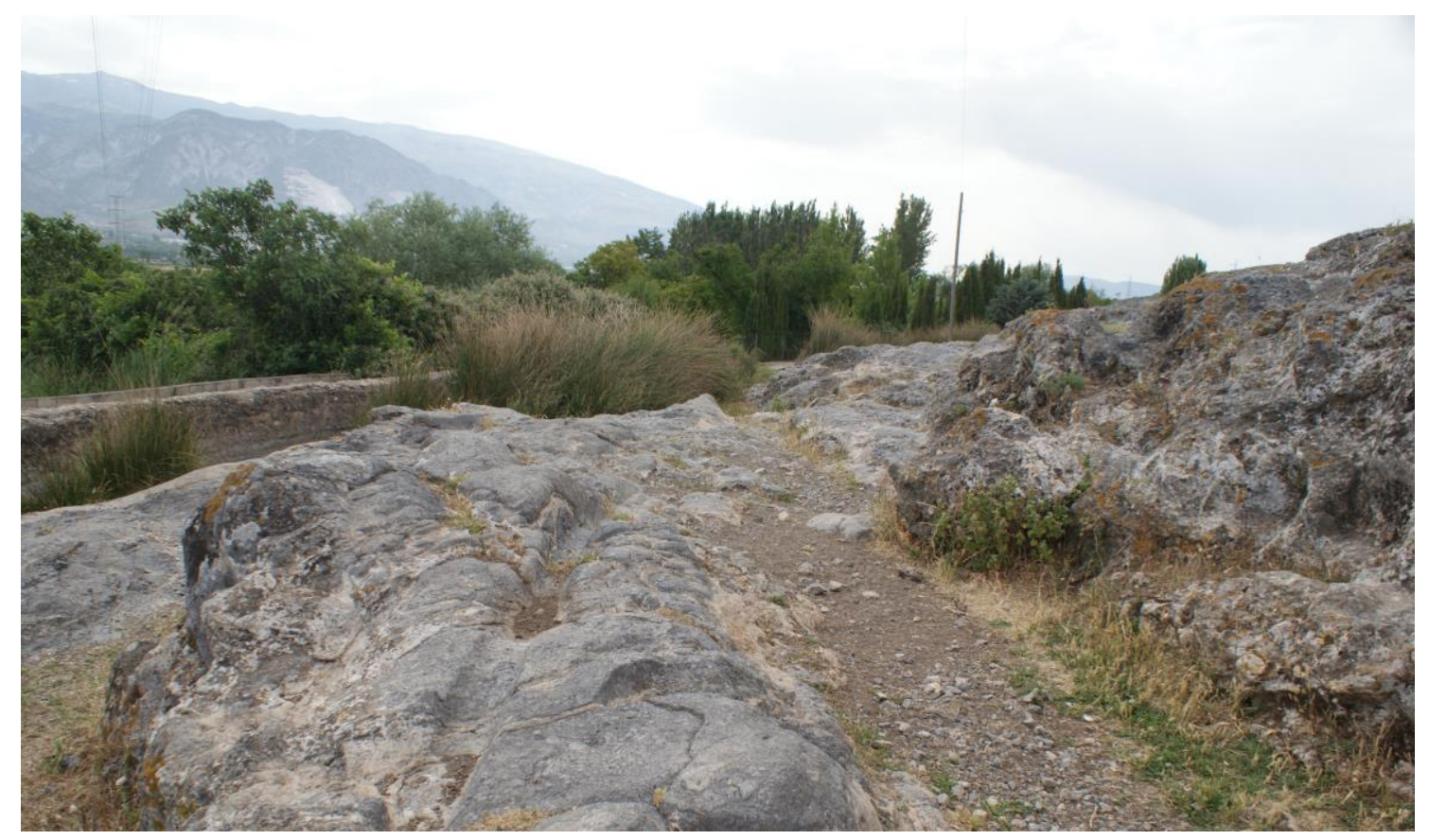

Fig. 3. Vía del período ibérico-romano en el cerro de los Molinos.

En época tardorromana, la información arqueológica vuelve a señalar la ocupación del perímetro de la laguna del Padul y de todo el corredor del valle en dirección a la costa ${ }^{5}$. Al igual que para los yacimientos de los Molinos y las Viñas el tipo de asentamiento que debió existir fue el tipo villae dedicadas a la actividad agrícola ${ }^{6}$.

En resumen, se puede señalar la existencia de un poblamiento preislámico en la zona oeste de la laguna del Padul, adjunto al camino que comunicaba la antigua ciudad de Elvira con la costa, sin descartar la existencia de otras villae en la actual ubicación del Padul, en un lugar elevado adjunto a una segunda vía de comunicación, entre la Alpujarra y Granada?

El asentamiento musulmán debió estar en una zona elevada, probablemente en el actual emplazamiento del pueblo del Padul y hasta el siglo XI-XII coexistió con las comunidades cristianas antes descritas. Posteriormente desaparecen las comunidades mozárabes siendo bien expulsados o eliminados como ocurrió en otros lugares del reino zirí8.

A la llegada de los musulmanes al Valle del Lecrín se fundan varias alquerías, entre ellas la del Padul o de al-Badūl con una organización y composición étnico-social similar a la del resto su Iqlim. Al parecer sólo se asentó un ŷund, tribu o familia en la alquería del Padul según el análisis de la información documental del siglo XVI ${ }^{9}$. El emplazamiento se realizó en una zona más elevada que los asentamientos preislámicos y lejos del área inundable de la laguna,

\footnotetext{
5 Yacimiento de Mondújar o de la finca de las bodegas Señorío de Nevada, en Cozvíjar. (García 2011, p.32).

6 También se ha documentado el hallazgo de sepulturas tardorromanas en el yacimiento de los Molinos, próximo a la fuente de Tabernas (Jabaloy 1985).

7 "no podemos descartar la presencia de asentamientos preislámicos en la zona urbana de la alquería , ya que la superposición estratigráfica del asentamiento habría eliminado los restos de los mismos" (García 2011, pp.39-40).

8 Ibid. p. 48.

9 Ibid. p. 42.
} 
en el lugar estable de las estribaciones de la Sierra de Manar, un lugar con pendiente donde actualmente se encuentra el pueblo. Es posible que el espacio urbano de la alquería del Padul se situase sobre algún asentamiento preislámico y debió evolucionar del mismo ${ }^{10}$.

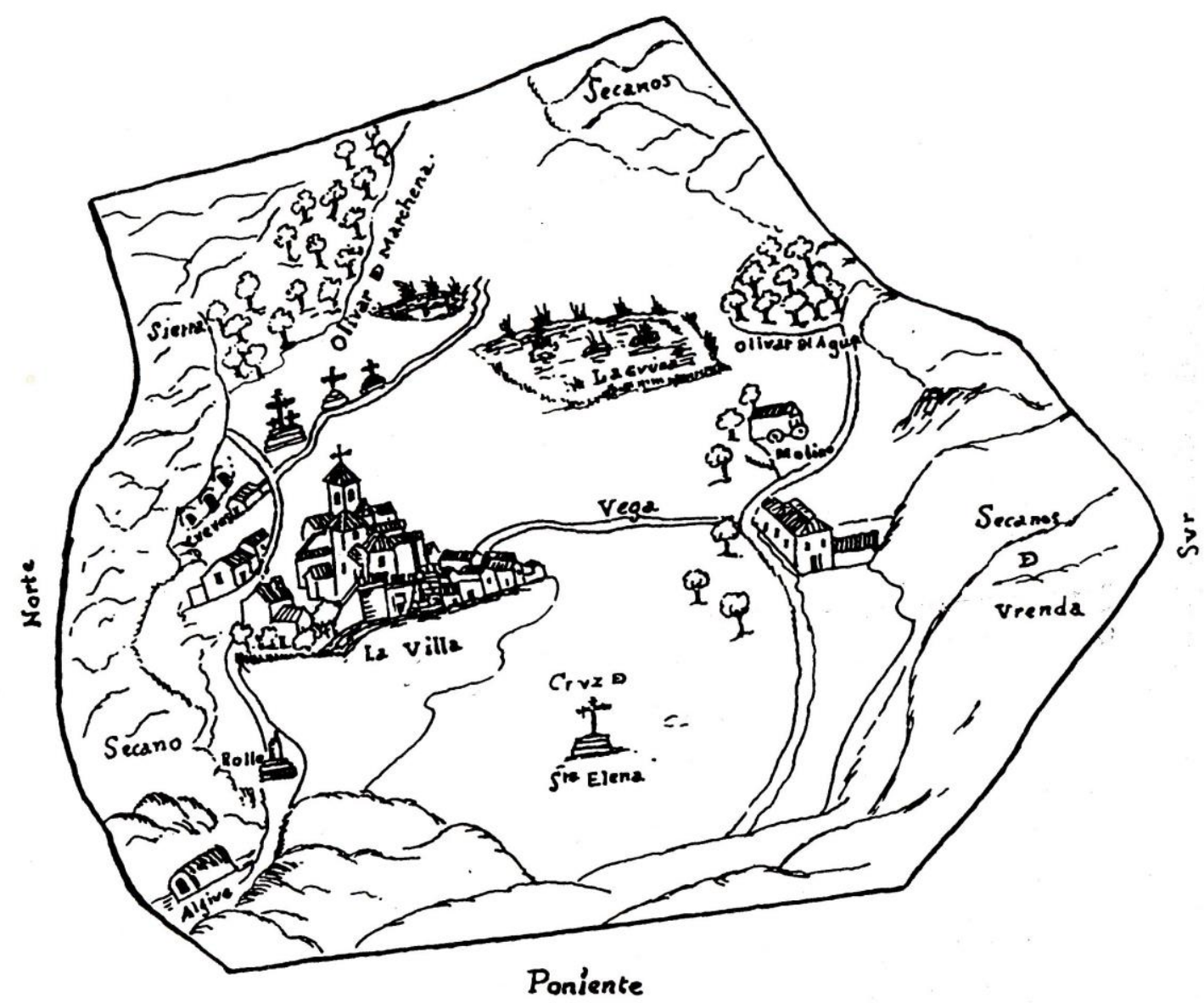

Fig. 4. Plano del Padul, Catastro del Marqués de la Ensenada 1752.

Asociada a la fundación de la alquería está la organización de su territorio y de sus espacios productivos, los nuevos pobladores serían los responsables del diseño y adaptación de las áreas de regadío a sus técnicas que, formarían parte de todo el conjunto de microsistemas hidráulicos implantados en el Valle del Lecrín. Es muy difícil establecer la cronología de las tierras de cultivo asociadas a la alquería, es posible que los sistemas más antiguos sean los coetáneos de Fuente de Tabernas y el pago de al-Ancón ${ }^{11}$. Lo que no queda claro aún es si estos sistemas de regadío existieron en época preislámica asociados a algún asentamiento tardorromano ya que, la toponimia señala esta posibilidad, al existir en toda la zona varios términos topográficos de raíz latina.

\footnotetext{
10 Ibid. p. 44.

11 Ibid.
} 
La estructura de la alquería debió mantenerse hasta la expulsión de los moriscos en época de conquista castellana, cuando desaparece la influencia musulmana y se instaura el modelo cristiano en el siglo XV.

Queda pendiente el estudio de la continuidad de la red hidráulica andalusí del Padul a la época cristiana y que cambios introduce la unidad social conquistadora en la organización de sus procesos productivos (Barceló 1996, p.55).

Un elemento asociado a la historia del Padul y de sus sistemas de riego es la "Laguna", un humedal que ha sufrido al menos dos procesos de desecación conocidos, ambos asociados al aumento de las áreas cultivables: el primero en época de dominación musulmana, en el período nazarí, cuando se desaguaba probablemente a través del río Cozvíjar (Delgado 2010, p.52) y el segundo acometido en el siglo XVIII (Villegas 1967, pp.566-567; Delgado 2010, pp.52-54), para el cual se construyeron una serie de canalizaciones conocidos a nivel local con el nombre de "madres" que convergen en el río de la Laguna o del Padul y que, desemboca en el río Dúrcal. Con estos procesos de desecación se aumentó de forma considerable el área de cultivo de regadío. Por esta circunstancia el humedal debe considerarse como un límite para la superficie cultivable, un término que cambió en al menos dos oportunidades conocidas por la acción humana y que afectó al territorio de forma significativa.

\section{Sistemas de riego tradicional del Padul}

La evidencia documental más antigua sobre los sistemas de regadío de la alquería de al-Badūl data de 1571 del libro del Apeo del Padul (Ferrer, 1994). Del análisis de este documento se conoce que los primeros sistemas fueron: el de la fuente de Tabernas, el de las albercas del pago de al-Ancón, el de la fuente del pueblo y el de Marchena, todos anteriores al siglo XVI ${ }^{12}$. El libro del Apeo también aporta datos de todos los sistemas de regadío existentes para entonces con mención de sus nombres, extensión, la procedencia del agua de cada uno de ellos y las normas que regían el reparto del agua (Carrasco 1998, p.288).

\subsection{Sistema de la Fuente de Tabernas}

El topónimo Tabernas parece responder a un origen romano (del lat. taberna, tienda-venta) ${ }^{13}$ y es el nombre con el que se conoce en el siglo XVI a la captación más antigua de todo el sistema de riego de la alquería, la balsa de Tabernas y que posiblemente este asociada a la primera zona con ocupación humana anterior a la etapa medieval ${ }^{14}$.

Desde la balsa de Taberna, hoy alberca de los Marquesitos, se irrigaron los pagos ${ }^{15}$ de: alHagia, Marcharguacil, el de Tabernas, el de al-Ancón y el de Fadin al-Basar.

El primer pago que se abasteció de la antigua balsa de Tabernas fue el de Marcharguacil con 75 marjales, el riego se realizaba por orden de propiedades, siendo el primero en regar el que

\footnotetext{
12 Existe un trabajo monográfico de 2011 sobre el territorio del poblamiento del Padul y es a partir del cual se han extraído la mayoría de datos históricos del presente trabajo (García 2011, p.85,110).

13 Ibid., p.83.

14 Ibid., p.83.

15 Con el término pago se define el espacio agrícola que presenta cierta homogeneidad física (Trillo 2009, p.114).
} 
más próximo se encontrara a la captación de agua (García 2011, pp.88-90; Carrasco 1998, p.290).

El segundo pago en recibir el agua de la misma balsa fue el propio de Tabernas que se abastecía además del agua de otra acequia que captaba el agua de la Fuente del pueblo (García 2011, p.93; Carrasco 1998, p.290). Adjunto a este pago debió estar el de Fadin al-Basar que linda con el de al-Ancón hacia el este y que al igual que el pago de Tabernas se abastecía con el agua de la balsa y de la fuente del Pueblo. La extensión de los pagos de Tabernas, de Fadin al-Basar y de al-Ancón en conjunto era de 1649 marjales, 60 estadales (García 2011, pp.9193).

El pago de al-Hagia de 233 marjales 68 estadales ${ }^{16}$ fue el último en recibir el agua de la balsa de Taberna y linda con la laguna. Su forma de riego era por turnos o Dula. El riego se ha venido haciendo con el agua de la Fuente del Mal Nombre que es canalizada en la acequia del Aguia, con la del río Aguia y con la de la balsa de Tabernas. El agua de la acequia solo podía utilizarse en el día pues en la noche el agua se reserva para los molinos de Feriche y de Paco Laguna. El pago del al-Hagia aumentó su área cultivable a partir de la última desecación de la laguna del siglo XVIII ${ }^{17}$.

\subsection{Sistema de albercas del pago de al-Ancón}

En la balsa de al-Ancón y en otras albercas se recogía y almacenaba el agua con la que se regaba el pago del mismo nombre. Esta balsa/alberca es del tipo "alberca manantial" ya que su técnica constructiva permitía la infiltración del agua del acuífero hacia el interior para su captación y posterior distribución. En el caso de la balsa de al-Ancón la entrada el agua se realiza por uno de sus muros y en la alberca de Palmones el agua brotaba por el fondo de la misma $^{18}$.

Este pago presenta unas condiciones topográficas de desniveles importantes lo que hizo necesario la construcción de bancales de cultivo. Se conocen además la existencia de varios manantiales como el del Ojo Oscuro y de fuentes como la Fuente de la Higuera dentro de este pago $^{19}$.

El riego de esta zona se ha visto alterado en época moderna por la ampliación de la tierra de cultivo, la adición de fuentes de agua como el manantial del pago del Roaero y la construcción de la EDAR en los años noventa ${ }^{20}$.

\subsection{Sistema de la Fuente del Pueblo}

Parte del agua de la Fuente del Pueblo se empleaba para el riego del pago de Fadin al-Basar y el de Dirdala, a través de la acequia del Pueblo que funcionó en conjunto con el sistema de

\footnotetext{
${ }^{16} \mathrm{El}$ área de cultivo que reporta el Catastro del Marqués de la Ensenada de 1752 para este pago es inferior, un análisis sobre este particular en (García 2011, p.87).

17 Ibid., pp.85-89.

18 Ibid., p.97.

19 Ibid., p.92.

20 Ibid., p.98.
} 
la Fuente de Tabernas a partir de su confluencia en las inmediaciones del pago de Dirdala (Ferrer 1994, p.26).

El agua que brotaba de la fuente se vertía en un canal por cinco caños de hierro y de allí pasaba al lavadero desde donde salía a la acequia que iba recogiendo el agua de otros nacimientos en su recorrido (Carrasco 1998, pp.28-29).

\subsection{Sistema de Marchena}

El sistema de riego de Marchena estaba formado en el siglo XVI por una serie de acequias que permitían el riego de los pagos de: Marchena, al-Calale la Alta, Handac-al-Garan y Quatrabija. La mayor parte del agua empleada para el regadío se captaba bien en el río Dúrcal o, en menos cantidad, provenía de las fuentes y manantiales existentes en la zona como es el caso de la alberca de Quatrabija. La acequia de Marchena capta el agua en el río Dúrcal desde donde comenzaba una conducción que repartía el agua entre las alquerías del Padul, de Dúrcal y la propia de Cozvíjar ${ }^{21}$. El reparto de agua entre las alquerías se hacía en partes iguales con la particularidad de que al Padul le correspondía además un derecho de Miadar22.

Con el agua proveniente de la acequia de Marchena se regaba el pago del mismo nombre entre los siglos XII y XIII y el pago de al-Calale la Alta, mientras que el pago de olivares de Handac-al-Garan y Cuatrabija se abastecían del agua de la alberca de Cuatrabija. Una vez que el agua entraba en la alquería del Padul el reparto de agua se realizaba por azadas ${ }^{23}$.

Tabla 1. Sistemas de regadío de la alquería de al-Badūlen el siglo XVI, relación de superficie irrigada.

\begin{tabular}{|c|c|c|}
\hline Nombre delSistema & $\begin{array}{l}\text { Nombre de la Superficie } \\
\text { Irrigada "pago" }\end{array}$ & Área $(\mathrm{Ha})^{24}$ \\
\hline Sistema de Tabernas & $\begin{array}{l}\text { al-Hagia, Marchaguacil, Taber- } \\
\text { nas, al-Ancón yFadin al-Basar }\end{array}$ & $\begin{array}{c}\text { al-Hagia }(14,23 \mathrm{Ha}) \\
\text { Marchaguacil }(3,96 \mathrm{Ha}) \\
\text { Tabernas, al-Ancón y Fadin al-Basar } \\
(87,17 \mathrm{Ha})\end{array}$ \\
\hline Sistema de al-Ancón & al-Ancón & Al-Áncón (8 Ha) \\
\hline $\begin{array}{l}\text { Sistema de la Fuente del } \\
\text { Pueblo }\end{array}$ & Fadin al-Basar & - \\
\hline $\begin{array}{c}\text { Sistema Acequia de Mar- } \\
\text { chena }\end{array}$ & $\begin{array}{l}\text { Marchena, al-Calale la Alta, } \\
\text { Hadac al-Garan y Quatrabija }\end{array}$ & $(32,76 \mathrm{Ha})$ \\
\hline
\end{tabular}

21 Ibid., p.100).

${ }^{22}$ (Ferrer 1994, p.27) "El significado de este vocablo suponía que en ciclos de seis días de riego, el último de ellos pertenece por completo a Padul durante todo el día y la noche" (García 2014, p.102).

23 "Azada de agua: la cantidad de agua que un regador puede ir guiando con la azada sin que se le vaya; se calcula que pueden ser unos 15 litros por segundo" (García 2011, p.102).

24 Para la conversión de las unidades de medición de superficie empleadas en el libro del Apeo del Padul (Ferrer 1994) Marjales y Estadales se ha establecido que un marjal equivale a 528,42 $\mathrm{m}^{2}$, equivalente a 100 estadales cuadrados (Espinar 1981, p.311; Escalona 2009, p.45). 
Durante el siglo XVII y principios del XVIII se amplía este el sistema de regadío incorporando una importante extensión de tierras antes de secano con la construcción de un nuevo ramal que se saca de la acequia del río Dúrcal, uno de estos ramales se conoce como la Acequia de los Hechos (García 2011, p.104).

\section{Estado actual del conocimiento del área de regadío en la cartografía.}

La primera fase del trabajo consistió en la recopilación previa de la documentación existente sobre los sistemas de regadío del Padul, su estudio, clasificación y registro en un Sistema de Información Geográfica. Una vez analizada la información se ha confeccionado una cartografía inicial donde se señalan el posible trazado las acequias de cada una de los sistemas de regadío y de los pagos asociados. En este apartado hay que resaltar el importante trabajo desarrollado por J. Félix García publicado en 2011 que debe considerarse como el primer estudio en profundidad sobre la alquería del Padul y punto de partida del presente estudio ${ }^{25}$.

La nueva planimetría se generó desde un Sistema de Información Geográfico que permitió localizar toda la información gráfica sobre la cartografía base georreferenciada del Instituto de Estadística y Cartografía de Andalucía IECA y la del Instituto Geográfico Nacional IGN.

Para la obtención de los mapas fue necesario generar un Modelo Digital de Elevaciones de la depresión de Padul a partir de los datos del IGN, PNOA de $5 \mathrm{~m}$ de resolución. También se georreferenciaron el trazado de las acequias y las superficies de regadío. Por último se localizaron los yacimientos arqueológicos y los restos materiales de la vía íbero-romana.

Con todos los datos puestos en conjunto sobre un mapa se pudo analizar la información de partida y se planteó la hipótesis de estudio del presente trabajo: la revisión de la superficie irrigada de la alquería para el siglo XVI en función de un elemento singular y cambiante que limita su extensión "La Laguna".

25 El trazado de las acequias y las superficies de regadío han sido extraídas del trabajo de J. Félix García que se basa en estudio del libro de Apeo de 1571 (Ferrer 1994) y de sus propias aportaciones producto de un trabajo de reconocimiento en campo. En dicha investigación, García ha combinado el estudio documental, el trabajo de campo, el estudio de la toponimia y la observación del espacio a partir de las fotografías aéreas, para la extracción de datos sobre los elementos y límites del espacio hidráulico obteniendo la primera reconstrucción planimétrica del sistema hidráulico original (García 2011). 


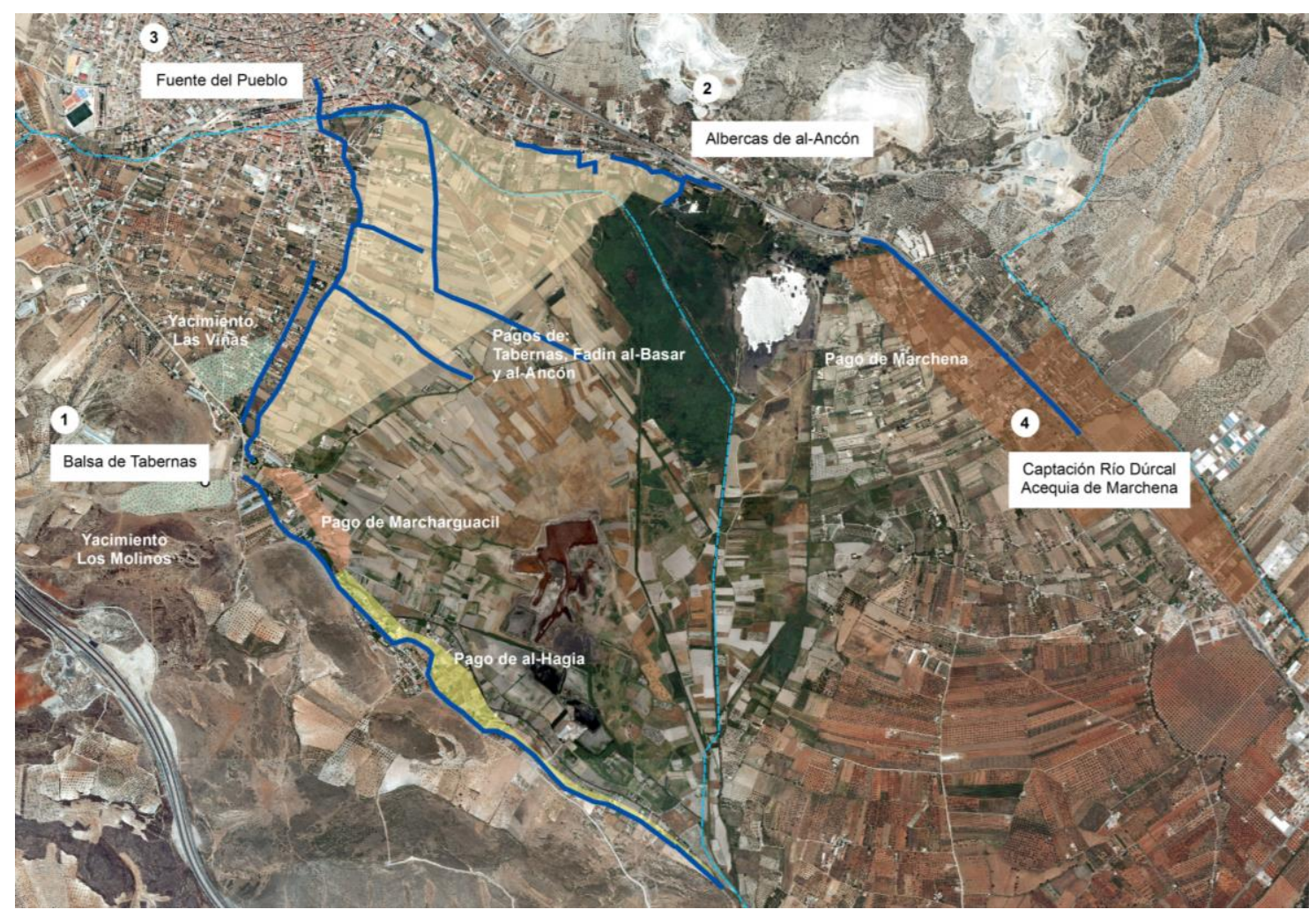

Fig. 8. Mapa de los sistemas de regadío y pagos existentes en la alquería del Padul para 1571, elaboración propia en base a la hipótesis de García (2011) ${ }^{26}$.

\section{La superficie de la laguna en el siglo XVI}

Para poder establecer una relación entre la superficie de regadío y la laguna es necesario intentar acercarnos al área que ocupaba el humedal para el siglo XVI. Ésta es la segunda fase del trabajo que propone y desarrolla una metodología específica para el cálculo aproximado de dicha área. El procedimiento se basa en determinar la cota a la cual estaría la superficie del humedal a partir de los datos reportados por la documentación histórica.

Para la determinación de la cota es necesario primero convertir la información histórica de la superficie del humedal al sistema métrico actual. Posteriormente se genera un Modelo Digital de Elevaciones de la depresión del Padul, desde donde se componen las curvas de nivel de cada $1 \mathrm{~m}$ de espaciado a través del SIG. Una vez obtenidas las curvas de nivel se procede a la determinación de la cota del nivel de la laguna a nivel de superficie, situación que se consigue extrayendo la curva de nivel cerrada de la depresión que compute un área que se corresponda con los datos de extensión del humedal en el siglo XVI.

Los datos históricos sobre la extensión de la laguna a finales del XVI provienen del libro del Apeo del Padul de 1571. En este documento se recogen las estimaciones del área del humedal realizadas por varios vecinos sin realizar ninguna medición, se reportan valores de entre 2.000 a 8.000 marjales.

26 Ortofotos del PNOA del IGN, vuelo 2010-2011. 
Un segundo documento que reporta valores de la extensión de la laguna es del siglo XVIII, anterior al segundo proceso de desecación, se trata de Catastro del Marqués de la Ensenada de 1752 en donde se reporta un área de 3.550 marjales.

Un tercer documento que se refiere al mismo asunto es el propio proyecto de desecación del humedal presentado en el Ayuntamiento de Granada en 1779 y en donde se reportan valores de entre 16.000 a 18.000 marjales. En opinión de Villegas este dato no se debe referir a la superficie inundada sino al área total de la depresión (Villegas 1967, p.566) y que el área propia del humedal debió ocupar alrededor de un tercio o un cuarto del total (Villegas 1967, p.569).

De la tabla 2 se puede apreciar la gran dispersión que existe en los datos obtenidos con valores entre 105,6 ha a 950,4 ha. Debido a tal situación, el primer paso será la determinación de la superficie actualmente ocupada por la depresión a partir del Modelo Digital de Elevaciones.

Lo primero que se ha computado en el presente trabajo es el área aproximada de la depresión que es de unas 650 ha y que está limitada por la cota 727 m.s.n.m. aproximadamente, gráficamente se puede ver la plataforma de la vega en el modelo fotorrelista 3D confeccionado en el presente trabajo (Fig. 6).

Tabla 2. Superficie de la laguna del Padul en las fuentes documentales

\begin{tabular}{ccc}
\hline Documento/Fecha & Área reportada & Área (Ha) \\
\hline $\begin{array}{c}\text { Libro del Apeo del Padul } \\
1571\end{array}$ & $2.000-8.000$ marjales & $105,6 \mathrm{Ha}-422,4 \mathrm{Ha}$ \\
$\begin{array}{c}\text { Catastro del Marqués de la } \\
\text { Ensenada } \\
1752\end{array}$ & 3.550 marjales & $187,44 \mathrm{Ha}$ \\
$\begin{array}{c}\text { Proyecto de Desecación de } \\
1779\end{array}$ & $16.000-18.000$ marjales \\
& & $844,8 \mathrm{Ha}-950,4 \mathrm{Ha}$ \\
Estimaciones de Villegas & $\begin{array}{c}\text { Un tercio o un cuarto del área } \\
\text { total de la depresión }\end{array}$ & $224,40 \mathrm{Ha}-299,2 \mathrm{Ha}^{27}$ \\
&
\end{tabular}

27 Para llevar a cifras las apreciaciones de Villegas en cuanto al área ocupada por la laguna a finales del siglo XVI se ha trabajado con un área total de la depresión de 17.000 marjales valor medio de entre 16.000 a 18.000 marjales que según sus apreciaciones se corresponde con el área total. 


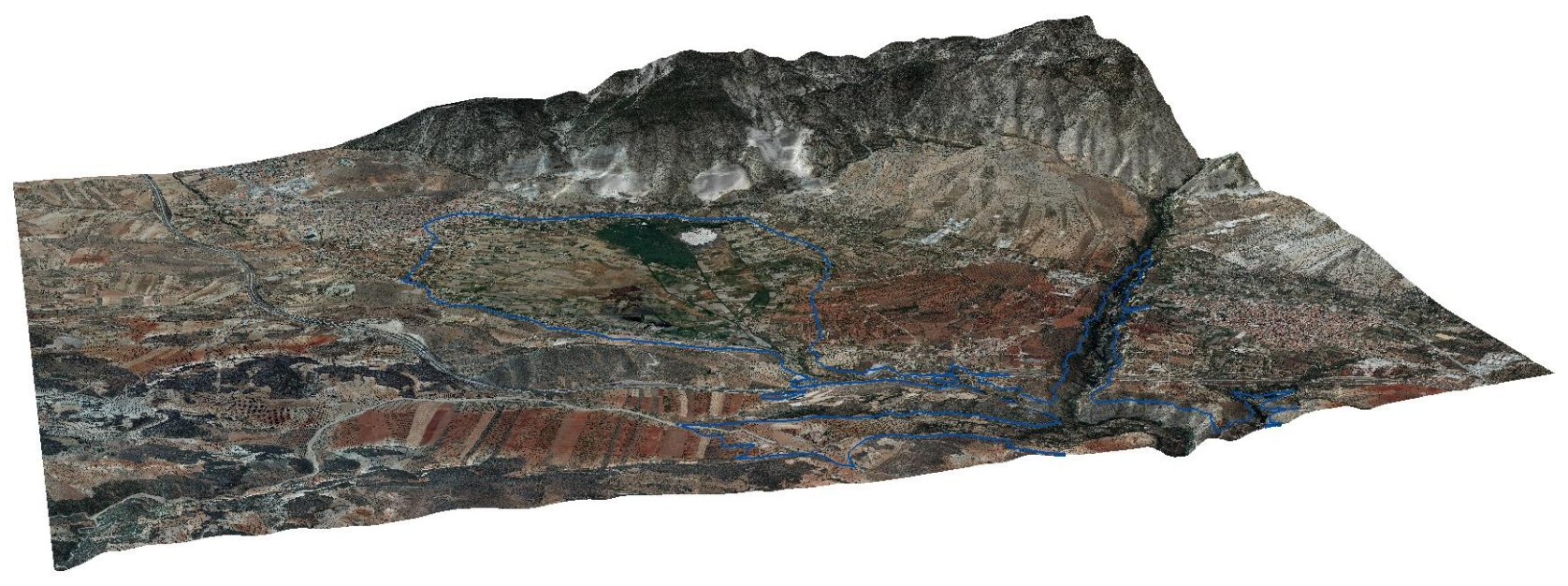

Fig. 6. Modelo 3d fotorrealista de la depresión del Padul. En azul se señala el área correspondiente a la depresión, cota 727 m.s.n.m. Elaboración propia.

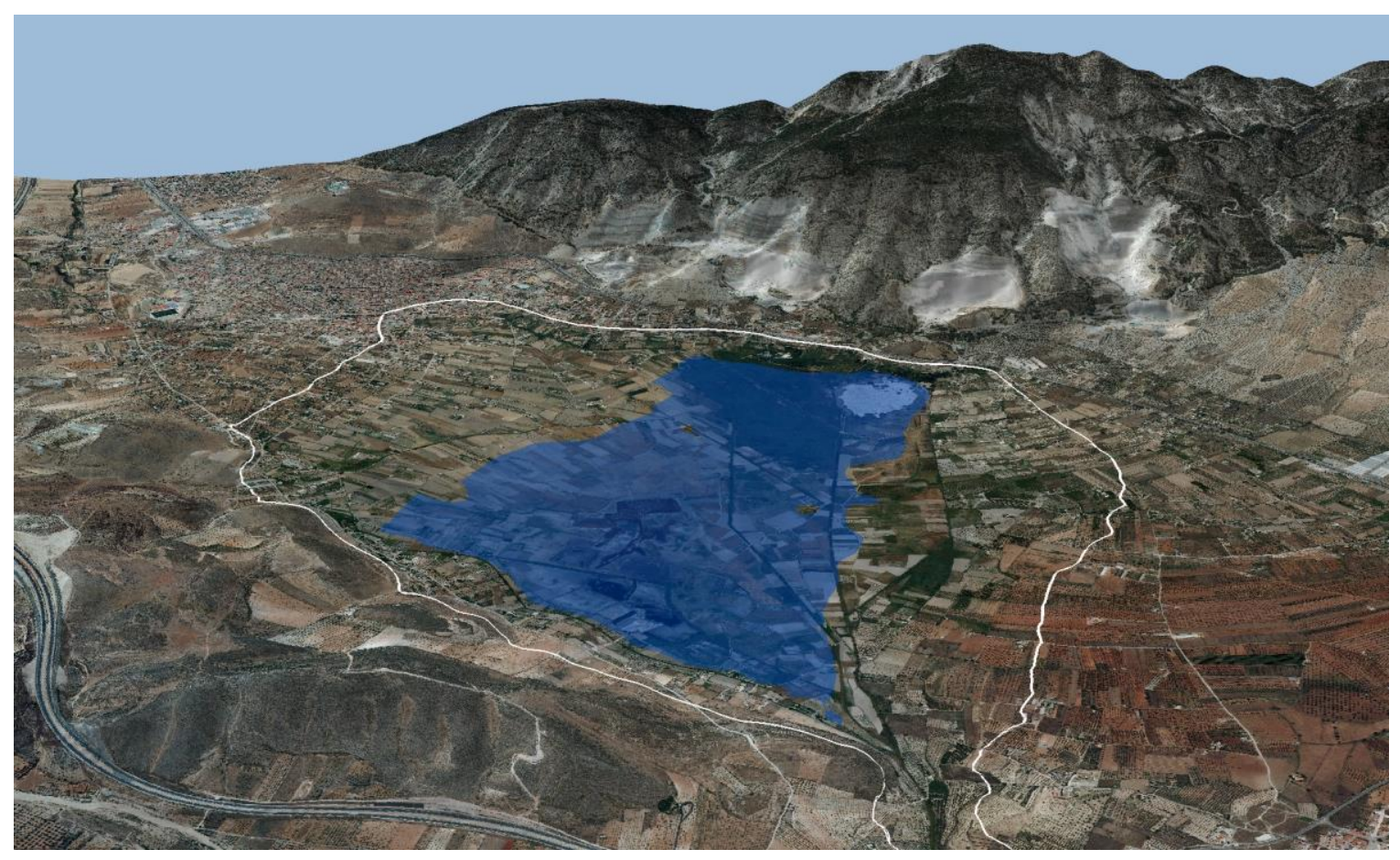

Fig. 7. Estimación del ámbito ocupado por el humedal para 1571 sobre modelo $3 \mathrm{~d}$ fotorrealista de la depresión del Padul. En blanco se señala el área correspondiente a la depresión. Elaboración propia. 
Con el área total de la depresión establecida en 650 Ha queda descartada el área del humedal reportada en el proyecto de desecación de 1779, un valor a todas luces desproporcionado. Siguiendo las estimaciones de Villegas el área de la laguna entonces estaría entre 162,5 ha a 216,6 ha, con un valor medio de 189,5 ha. Esta cifra es muy cercana a la que reporta el Catastro del Marqués del Ensenada de 1752 y es el dato que se tomará como base para la determinación del área ocupada por el humedal en ese momento histórico.

Para determinar espacialmente el área ocupada por la laguna, su planta, en base a un área estimada de 189,5 ha se realiza el proceso inverso a anterior, que es localizar de todas las curvas de nivel cerradas generadas desde el Modelo Digital de Elevaciones la que compute una superficie similar a la estimada. De este análisis resulta que el área ocupada por la laguna se corresponde con la actual curva de nivel de 725 m.s.n.m. El ámbito ocupado por el humedal es la que se muestra en la Fig. 7.

\section{El humedal, límite de las tierras de cultivo}

La hipótesis de la superficie del humedal para finales del siglo XVI se ha relacionado con las figuraciones planteadas sobre el espacio ocupado por los pagos de regadío para el momento (Fig.8).

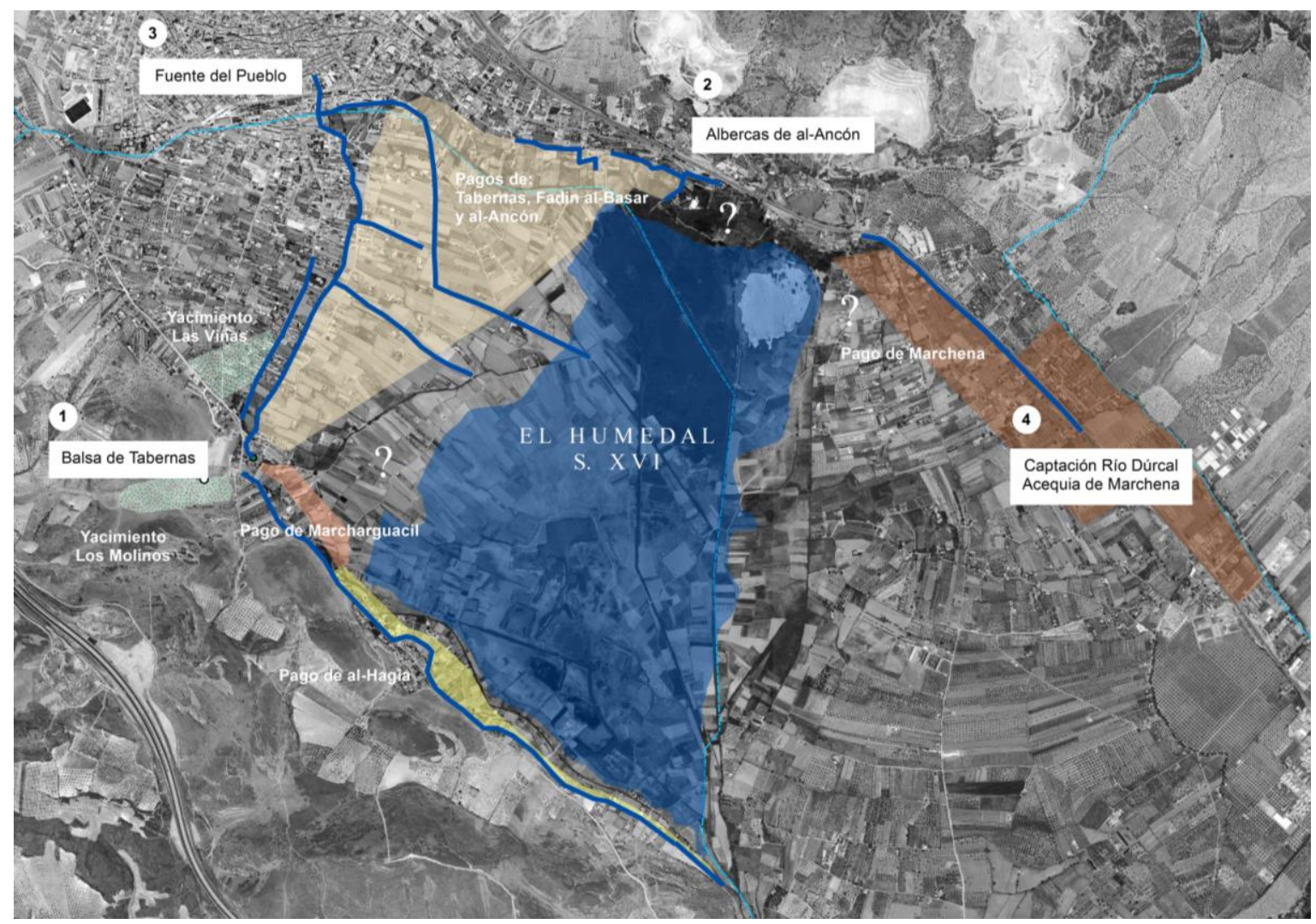

Fig. 8. Hipótesis del área ocupada por el Humedal del Padul y sus Sistemas de Regadío en el siglo XVI.

La puesta en conjunto de la información permite establecer una serie de conclusiones preliminares sobre la disposición de los pagos frente a la laguna. Una de ellas es que la mayoría 
de las áreas en explotación debieron configurarse siguiendo el perímetro del humedal dejando un margen suficiente de tierra inculta, la parte fangosa que se aprovechaba con otros usos. El pago de al-Hagia es el único que cumple con esta condición tal y como está definido actualmente según la propuesta de García (2011, p.90), aunque la franja de retranqueo con respecto al humedal es muy grande. No ocurre lo mismo con el resto de los pagos: Marcharguacil, Tabernas, Fadin-al Basar y al-Ancón y Marchena que se ajustan parcialmente o no se ajustan a los límites de la laguna.

Para estas nuevas interrogantes deben surgir nuevas hipótesis para contrastar con necesarias prospecciones en campo, además se debe realizar un relectura de la información documental histórica en cuanto a los linderos de cada una de las extensiones de regadío, prestando especial atención a los referidos al humedal.

\section{El pago de al-Hagia y la acequia de al-Hagia, un ejercicio del trabajo en campo}

En este apartado se realizan una serie de análisis se intenta aportar más datos para precisar el área de cultivo que conformó el pago y su relación con su entorno inmediato -la lagunacomo límite de las tierras de cultivo, además de realizar una valoración que nos aproxime a la cantidad de agua que debió transportar esta acequia.

\subsection{La superficie del pago de al-Hagia, cuestiones por resolver}

Para avanzar en el conocimiento de la organización espacial de los sistemas de regadío del Padul a finales del XVI, se realizó un trabajo de campo, un ejercicio que incluyó una serie de tareas de reconocimiento y toma de datos de sus elementos hidráulicos, como la georreferenciación y el registro de algunas de sus características. Para este primer reconocimiento se seleccionó un subsistema del conjunto, pues su objetivo final es el de proponer una nueva metodología a aplicar in situ al resto del regadío de la alquería en futuras investigaciones.

De todos los sistemas se ha escogido el de Tabernas, específicamente se ha estudiado la acequia de al-Hagia que suministraba agua al pago del mismo nombre. La elección de este subsistema se debe a que, por un lado se trata de uno más antiguos y por otra parte que su estado del conocimiento plantea una serie de interrogantes.

La información existente sobre la extensión del pago de al-Hagia en la documentación histórica es discordante. En el Apeo del Padul de 1571 se cita contó con 233 marjales 68 estadales más 36 marjales 50 estadales de olivar, un total aproximado de 14,23 (Ferrer 1994), mientras que las mediciones de 1752 del Catastro del Marqués de la Ensenada, se reportan $\tan$ solo 68 marjales equivalentes a 3,59 ha. Esta diferencia tan importante fue analizada en 2011 por García concluyendo que no existen datos suficientes que permitan explicar tal variación y aportando una serie de hipótesis que intentan dar respuesta a esta situación. Una de estas hipótesis plantea que debió existir en el pago del al-Hagia "una zona limítrofe que no era susceptible a la puesta en explotación hasta que se lleva acabó su desecación en 1779", esta zona estaba afectada por el constante crecimiento del área de la laguna y por tal motivo se entiende que en 200 años el humedal le ha ganado terreno al área cultivada.

Según los cálculo hechos en la presente investigación la propuesta de García de 2011 plantea que el área del pago de al-Hagia debió ser de unas 10,7 ha, un valor intermedio entre los dos 
anteriores y que es producto del reconocimiento in situ del pago y que incluye un estudio toponímico ${ }^{28}$.

Tabla 3. Diferentes hipótesis sobre la extensión del pago de al-Hagia en el siglo XVI.

\begin{tabular}{ccc}
\hline Documento/Fecha & Área reportada & Área (ha) \\
\hline $\begin{array}{c}233 \text { marjales, 68 estadales } \\
\text { Libro del Apeo del Padul } \\
1571\end{array}$ & 14 marjales, 50 estadales \\
$\begin{array}{c}\text { Catastro del Marqués de la } \\
\text { Ensenada } \\
1752\end{array}$ & 68 marjales & 3,59 ha \\
Hipótesis gráfica García & & \\
2011 & - & 10,7 ha \\
\end{tabular}

Tanto en 1571 como en 1752 la superficie de regadío del pago de al-Hagia estaba limitada por la laguna, situación que se mantuvo hasta su desecación a finales del XVIII. La pregunta que habría que responder es si el aumento del terreno anegado por el humedal por falta de mantenimiento de sus drenajes en 200 años justificaría una diferencia de más de $10 \mathrm{Ha}$ entre las dos mediciones.

Del análisis realizado en este trabajo sobre la posible extensión del humedal en el siglo XVI también se pueden extraer datos sobre el área ocupada por el pago del al-Hagia. Observando en detalle la Fig. 8 vemos que tal y como se plantea la disposición del pago existe un margen de terreno inculto entre éste y la laguna muy importante, una franja de unos $80 \mathrm{~m}$ promedio. Esta área bien pudo computar unas 10 ha o más por lo que, o el pago era más grande o lo era el humedal, pues desde un primer análisis este margen de terreno inculto resulta excesivo.

Es posible aumentar área del pago para ajustarlo a las 14,23 ha reportadas por el Libro de Apeo, pero esta situación debe estar acompañada de una nueva campaña de campo que permita establecer in situ el límite más probable entre el pago y el humedal.

Se pueden obtener más datos sobre este aspecto si se continúa el estudio haciendo el mismo análisis para el resto de los pagos colindantes con la laguna que, en principio y desde las hipótesis planteadas en trabajos anteriores, no se ajustan a su perímetro.

Otro aspecto a tener en cuenta para futuras investigaciones son las modificaciones del relieve de la depresión ocurridas tras el proceso de desecación a finales del XVIII para realizar el parcelario que actualmente existe en la vega. Se propone continuar el trabajo confeccionando un Modelo Digital de Elevaciones que tenga en cuenta los cambios de relieve que pudieron haber ocurrido en la depresión en los últimos 400 años basados en un estudio documental previo.

28 Las 10,7 ha. han sido calculadas en el presente estudio a partir del dibujo de la extensión del pago del alHagia de la figura 17 en un SIG (García 2011, p.90). 


\subsection{Caudal de la acequia de al-Hagia, superficie irrigada}

El objetivo de este análisis es el de proponer el estudio de los espacios de regadío a través de estimaciones de la cantidad de agua disponible a través de sus acequias y los posibles cultivos desarrollados para intentar determinar los valores de diseño empleados en sus sistemas de regadío.

Para aproximarnos a la cantidad de agua transportada por la acequia de al-Hagia en el siglo XVI se han realizado una serie de mediciones en campo sobre la canalización actual para determinar el trazado en planta de la acequia medieval y sus posibles secciones transversales. Con estos datos se procede al cálculo hidráulico correspondiente para cuantificar el posible caudal transportado por la canalización.

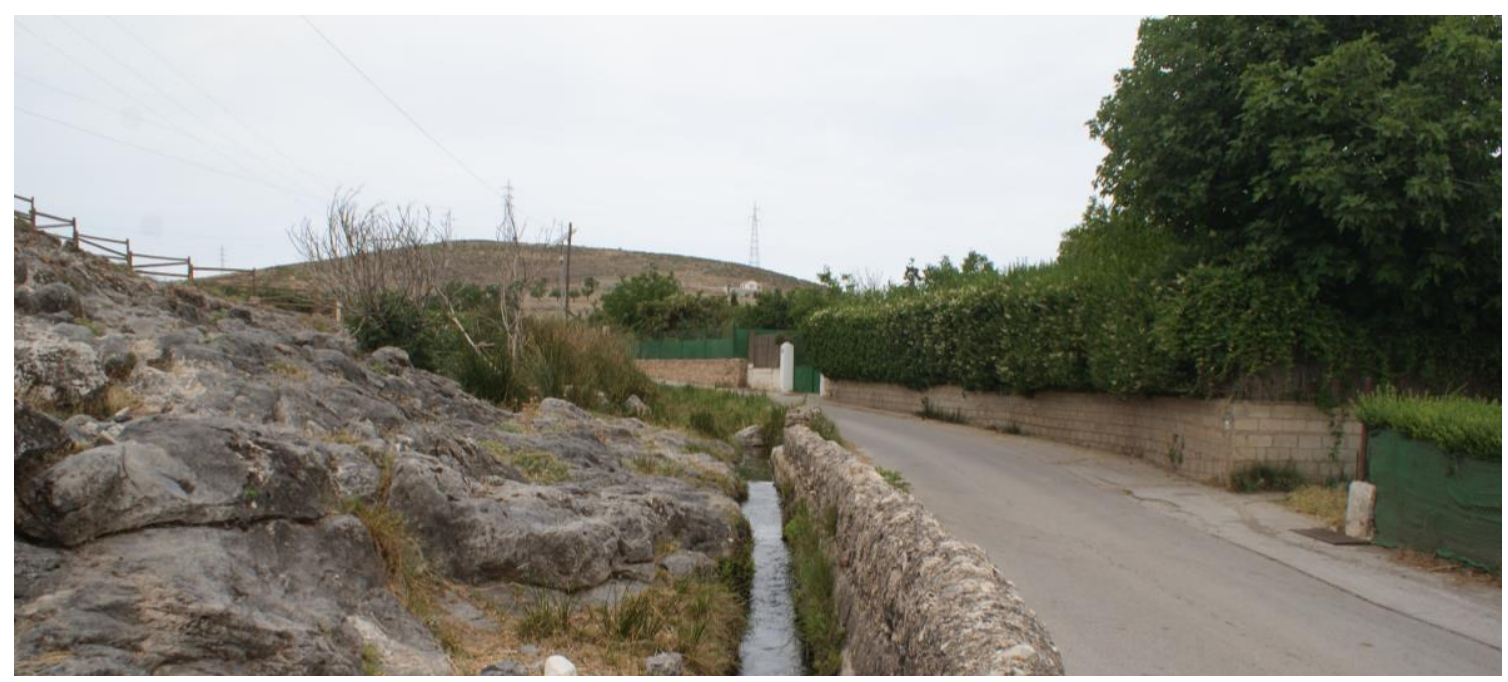

Fig. 9. Acequia de al-Hagia en la actualidad junto al paso de la vía íbero romana, cerro de los Molinos.

Para la estimación de la capacidad hidráulica de las canalizaciones se ha aplicado la fórmula de Manning $\mathrm{v}=\left(\mathrm{Rh}^{\wedge} 2 / 3 . I s^{\wedge} 1 / 2\right) / n$, donde: $\mathrm{v}$ es la velocidad media del flujo, Rh es el radio hidráulico, Is es la pendiente longitudinal de la conducción y $n$ es el coeficiente de rugosidad de Manning ${ }^{29}$.

Las secciones transversales medidas fueron p1, p2 y p3 en la actual acequia del al-Hagia, con valores de ancho de canal y altura de la lámina de agua variables. La longitud de la acequia está en torno a unos $2200 \mathrm{~m}$ y su pendiente longitudinal es de $0,0013 \mathrm{~m} / \mathrm{m}$. Estos son datos actuales solo sirven para calcular una primera medida de caudal de agua, una aproximación a la situación existente en el siglo XVI en orden de magnitud. Introduciendo los datos en la formulación correspondiente se obtiene un valor de caudal de agua entre los 60 y los $70 \mathrm{l} / \mathrm{sg}$.

Con los valores de caudal de agua antes calculados podemos intentar acércanos al área potencialmente regada por la acequia asumiendo que, en el mes de máximo consumo, un sistema de regadío por gravedad actualmente se proyecta en base a una demanda "media" de

29 Las formulación a aplicar parten de asumir un flujo de tipo uniforme, que se rige por las ecuaciones más reducidas de continuidad y dinámica: $\mathrm{Q}=\mathrm{v}$.A, donde: $\mathrm{Q}$ es el caudal, $\mathrm{v}$ es la velocidad media y A es la sección hidráulica transversal del flujo. Además: $I e=I s$, donde: Iees la pendiente de la línea de energía y $I s$ es la pendiente longitudinal de la conducción. 
$0,8 \mathrm{l} / \mathrm{s} / \mathrm{ha}$. Con esta cifra podemos decir que para un caudal transportado por la acequia de $60 \mathrm{l} / \mathrm{s}$ y con un consumo medio de $0,8 \mathrm{l} / \mathrm{s}$, la canalización del al-Hagia estaba en capacidad de abastecer a $75 \mathrm{Ha}$, un valor muy por encima del reportado en 1571 de 14 ha. Estos cálculos pueden ajustarse aún más, pues el valor de demanda "media" de $0,8 \mathrm{l} / \mathrm{s} / \mathrm{ha}$ depende a su vez del tipo de cultivo que varía mucho según los requerimientos hídricos, pudiendo hasta triplicar esta cifra. Pata tal situación, se necesitarían entonces $2,4 \mathrm{l} / \mathrm{s}$ / ha y que con la aportación de agua establecida en $60 \mathrm{l} / \mathrm{s}$ resulta que sólo se podrían regar 25 ha.

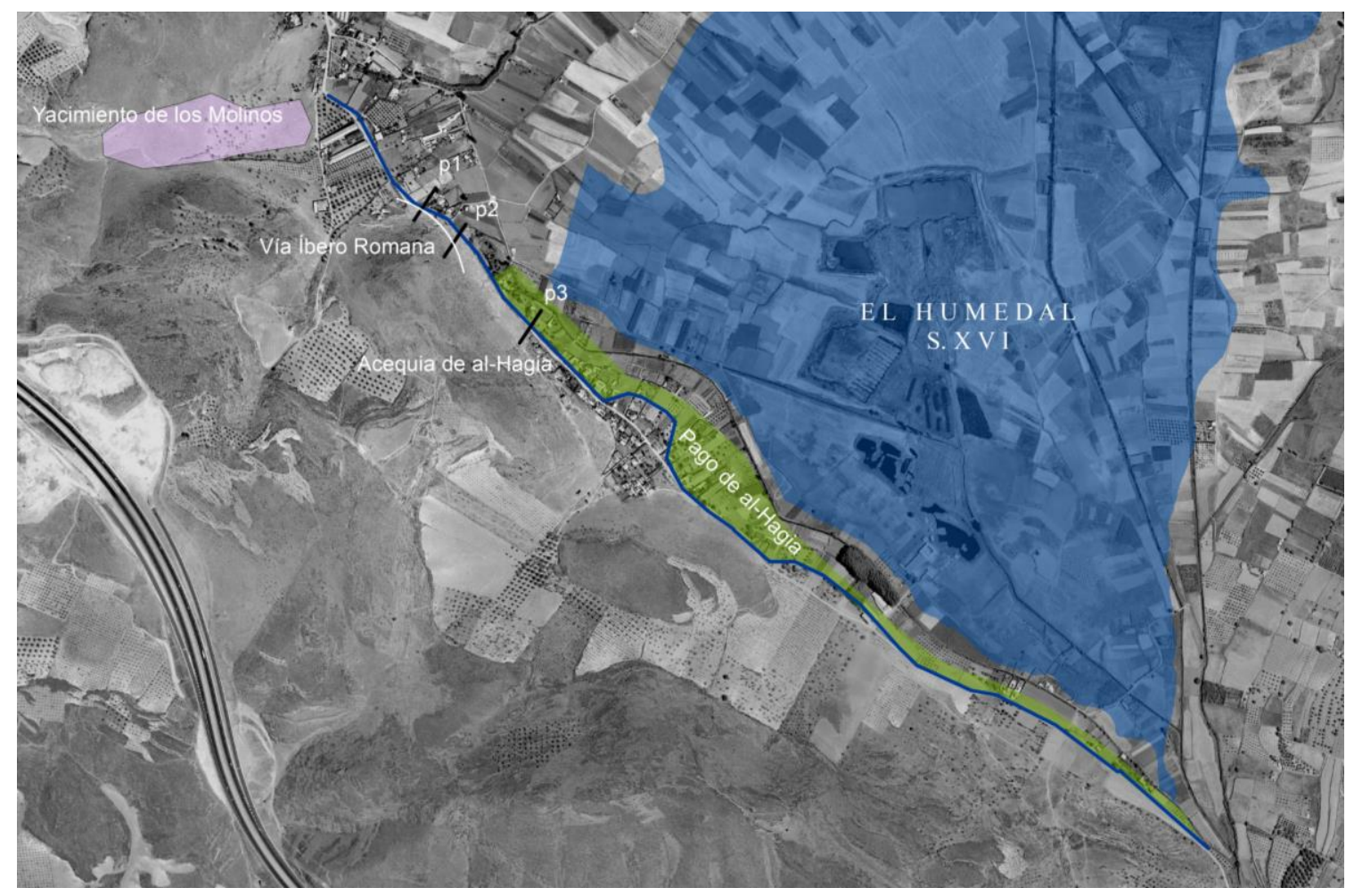

Fig. 10. Sistema de Tabernas, subsistema de al-Hagia, siglo XVI.

Un segundo análisis se puede plantear a través del dato conocido de que algunos de los pagos de la alquería del Padul se regaban por azadas, como costa en libro de Apeo de 1571 para el pago de Marchena. Una azada se corresponde con una caudal de agua que un trabajador puede manejar sin que se le vaya y ha sido estimado en trabajos previos en unos $15 \mathrm{l} / \mathrm{s}-20$ l/s, siendo $40 \mathrm{l} / \mathrm{s}$ un valor frecuente. La azada es lo que actualmente se conoce como "Módulo" en los actuales diseños de riego por gravedad y depende de las costumbres de la zona, del tamaño de los bancales y de la permeabilidad del suelo (Vallarino 1997, p.64). Se propone revisar nuevamente el libro de Apeo del Padul para precisar el agua empleada por cada subsistema y relacionarlo con un área conocida, con los tipos de cultivo y empezar a confeccionar una base de datos que permita determinar los parámetros de diseño hidráulico específicos del momento.

A manera de conclusión se puede decir que en el estado actual del conocimiento del subsistema de regadío de al-Hagia no se puede fijar aún un valor de caudal/área irrigada. Se puede decir que el caudal de agua que transporta la actual acequia es capaz de regar un área mucho mayor que la establecida en el libro del Apeo de 1571 de 14 ha. Se debe profundizar la investigación intentando conocer las dimensiones de la acequia medieval, así como el tipo 
de cultivo desarrollado en el pago, pues estos datos son los que permitirán obtener cifras más precisas.

\section{Análisis de resultados y conclusiones}

Los sistemas tradicionales de regadío del Padul del siglo XVI estaban conformados por estructuras hidráulicas con un importante valor histórico, su fecha de construcción es desconocida y es probable que las primeras estructuras de canalización del agua adjuntas al yacimiento de los Molinos estuvieran en funcionamiento en un período premusulmán.

Los espacios irrigados se fueron extendiendo en el espacio fértil disponible en el perímetro de la laguna, un elemento que fue frontera del crecimiento del área cultivable hasta su desecación en el siglo XVIII.

El presente trabajo plantea una nueva forma de entender el funcionamiento de espacios productivos "pagos" a partir del cálculo del área ocupada por la laguna en el siglo XVI, ya que muchos de ellos tenían como límite las zonas fangosas frontera del humedal. Se propone aproximarnos a estas áreas de regadío desde un estudio conjunto de la información documental, el análisis del relieve desde los Modelos Digitales de Terreno, los estudios toponímicos y la prospección hidráulica en campo, para intentar aportar más datos al conocimiento de la técnica hidráulica en al-Andalus (Trillo 2003; Malpica 1995).

Existe un campo abierto en el que la ingeniería hidráulica tiene mucho que aportar a través del cómputo de caudales potenciales de riego y su relación con la superficie irrigada, el tipo de riego, los tipos de cultivo y la clasificación del suelo. Se ha planteado una metodología a aplicar para seguir avanzando en esta clase de estudios que parte de la determinación de todas las características de los elementos de conducción de agua, el cálculo de su capacidad de transporte, el conocimiento del tipo de cultivo y suelo para poder obtener una relación de agua aportada a cada unidad de regadío.

En esta investigación no han sido abordadas las cuestiones planteadas en estudios precedentes sobre desarrollo de la parte habitada de la alquería medieval que, en el caso del Padul, no responde los modelos de emplazamiento "sobre la línea de rigidez determina por la acequia principal" (Glick 1992; Glick 1996), ya que excede el objeto de estudio. No obstante, nos permitimos hacer una reflexión al respecto y es que quizás esta situación singular se deba a que la gran parte de los espacios irrigados de época islámica del Padul, cerca del $70 \%$ del regadío, se concentró en el nor-oeste de la laguna, justo por debajo de la zona urbana de la alquería. Los pagos de Tabernas, Fadin al-Basar y al-Ancón eran los que tenían posibilidad de crecer frente al humedal, mientras que los pagos del sur-oeste ya estaban al límite en cuanto al crecimiento. Es posible que los pagos de Marcharguacil y de al-Hagia estén asociados a los primeros asentamientos en el territorio, situación que se justifica si se tiene en cuenta la cercanía con los yacimientos de los Molinos y de las Viñas además de la vía romana, lugares ideales para el emplazamiento de villae que, debieron cumplir un papel importante en el desarrollo agrícola de la zona. 


\section{Referencias}

Barceló, M.(1996): El agua no duerme. Fundamentos de la arqueología hidráulica nadalusí, Granada: El Legado Andalusí.

Carrasco, M. (1998): El Padul, Granada: Ayuntamiento de la Villa del Padul.

Delgado, J.A.(2010): La laguna de el Padul. El gran humedal de Granada. Garnata, 1era quinc(11), pp.47-59.

Escalona, M.(2009): Estadal. Una aproximación al universo de la Mensura, Sevilla: Consejería de Agricultura y Pesca de la junta de Andalucía.

Espinar, M.(1981): Medidas de peso, capacidad y otras en las Alpujarras según los libros de habices. Cuadernos geográficos de la Universidad de Granada, 11: 309-318.

Ferrer, M.(1994):Libro de Apeo y Repartimiento de suertes del lugar del Padul.1571, Granada: Ayuntamiento de Padul.

García, J.F.(2014): Diseño hidráulico de origen medieval en la zona norte del Valle del Lecrín: Transformación histórica de los agroecosistemas de la alquería de Dúrcal. Revista del Centro de Estudios Históricos de Granada y su Reino, 26: 93-132.

García Pérez, J.F.(2011): Territorrio y poblamiento medieval en el valle del Lecrín. La alquería de Padul., Granada: Kadmos.

Glick, T.H.(1996): Irrigation and Hydraulic Technology, Variorum.

Glick, T.H.(1992): Tecnología, ciencia y cultura en la España medieval, Madrid.

Jabaloy, M.E.(1985): Dos nuevas sepulturas romanas en la provincia de Granada. Cuadernos de Prehistoria de la Universidad de Granada, 10: 367-375.

Kirchner, H. \& Navarro, C.(1996): Objetivos, Métodos y Práctica de la Arqueología Hidráulica. In El agua que no duerme. Fundamentos de la arqueología bidráulica andalusí. pp. 91-118.

Malpica, A.(1995): El agua en al-Andalus. Un debate historiográfico y una propuesta de análisis. V Semana de Estudios Medievales, pp.65-85.

Rodríguez, M.O. (1985): Carta arqueológica de la Hoja Padul (1026-II-IV): la población prehistórica y antigua en el sector oriental de la Vega de Granada y la depresión de Padul. Universidad de Granada.

Trillo, C.(2003): Agua y paisaje en Granada, Granada, Diputación de Granada.

Trillo, C.(2009): El agua en al-andalus, Editorial Sarriá.

Vallarino, E.(1997): Obras Hidráulicas, Madrid: E.T.S. Ingenieros de Caminos, Canales y Puertos de Madrid.

Villegas, F.(1967): Laguna del Padul: evolución geológico-histórica. Estudios Geográficos, 18: 561-576. 